\title{
Predictive Factors for the Sense of Community Belonging Among Older Adults in Lower Northern Thailand
}

\author{
Nithra Kitreerawutiwong (iD) ${ }^{1,}$, Orawan Keeratisiroj (iD) ${ }^{1}$ and Sunsanee Mekrungrongwong (iD ${ }^{1}$ \\ ${ }^{1}$ Faculty of Public Health, Naresuan University, Phitsanulok, Thailand \\ "Corresponding author: Assistant Prof, Faculty of Public Health, Naresuan University, Phitsanulok, Thailand. Tel/Fax: +98-66897048920, Email: nithrakm@gmail.com
}

Received 2020 May 23; Revised 2020 September 05; Accepted 2020 September 18.

\begin{abstract}
Background: Sense of belonging (SOB) is fundamental to our health, social interactions, and psychological functioning. However, older adults usually feel a loss in social belonging.

Objectives: This study aimed to investigate factors influencing SOB to the community among older adults in a rural community. Methods: 1,098 older adults were selected using multistage sampling. Data were collected using a questionnaire, including demographic characteristics, social support, neighborhood environment, and SOB aspects. To assess the reliability, a correlation coefficient of 0.72 was calculated for social support, neighborhood environment (0.82), and SOB aspects (0.88). Data were analyzed using descriptive statistics and multiple regression analysis.

Results: The mean score of SOB was $50.85 \pm 7.44$, which is acceptable. The results showed that social support, neighborhood environment, duration of living in the community, and education higher than the fourth grade were positive predictors for the SOB. Conclusions: This study indicated that improving the neighborhood environment and providing social support for rural older adults can enhance their SOB to the community. Also, the duration of living in the community and education have significant impacts on the SOB to the local community.
\end{abstract}

Keywords: Neighborhood, Older Adults, Sense of Belonging, Social Support

\section{Background}

A sense of belonging (SOB) is defined as the sense of psychological involvement in a system or environment so that the individual feels personally accepted by others and shares the beliefs and interests of other community members $(1,2)$. SOB is associated with greater social and psychological functioning of individuals (3). Moreover, SOB is closely connected to the increased sense of security and encourages people to participate in community activities (4). Therefore, SOB to a community empowers older adults to cope with life challenges and to maintain or improve their well-being (5).

The dimensions of SOB include membership, influence, reinforcement integration of fulfillment needs, and shared emotional connection. Kissane and McLaren (6) concluded that a greater SOB to the community is associated with higher motivation in life, child-related concerns, responsibilities toward family, and survival and coping beliefs, especially among older adults. Moreover, SOB is an important mental health concept (7), as low levels of the SOB to the community are believed to be associated with higher rates of depression (8). Therefore, as SOB influences both physical and psychological well-being, it is a vital public health concern.

Based on the literature, the number of years living in a community, neighborhood environment, and employment are the main contributors to the SOB. It worth noting that the literature review revealed no association between gender and SOB (9). Also, satisfaction from the neighborhood influences the SOB (10), since individuals feel belonging to the neighborhood through a personal identity tied to a place (11). Therefore, the neighborhood environment strongly affects establishing and maintaining supportive relationships in the community.

Social support includes emotional, psychological, and material resources provided by one's social ties (12). Adequate social support enhances social relationships and strengthens positive interactions with others (13). Since lack of social support creates barriers to meeting physical and emotional needs, it is believed as a social determinant of health. Besides, it is associated with mental health problems (14). Older people are faced with several complex problems in the fields of physical, mental, and so- 
cial health. Therefore, adequate social support empowers them to stay in their familiar neighborhood environment and maintain their social ties, which turn into improved health.

As mentioned earlier, sociodemographic factors are believed to influence SOB; however, little attention has been paid to social support and neighborhood environment. Since 2005, Thailand has become an aging population, with more than $10 \%$ of the population aged above 60 . During the past decade, the proportion of the older adult population has increased continuously, from $13.2 \%$ in 2010 to $16.06 \%$ in 2018 . In 2016 , older adults accounted for $22 \%$ of the population in northern regions, which is the highest in the country (15). Hence, due to the increased share of older adults on the total population, the government has begun to reconstruct the economic and social infrastructures by promoting the collaboration of different sectors to respond to the future needs of the community. SOB to the community is extremely limited among older adults. Therefore, identifying factors predicting SOB to the community among older adults would be useful for designing appropriate programs to enhance their SOB to the local community.

\section{Objectives}

This study aimed to investigate SOB to the community among older adults and to examine factors predicting SOB in Lower Northern Thailand.

\section{Methods}

This study had a cross-sectional design. Data were collected from October 2017 to September 2018.

\subsection{Study Population}

The study population consisted of those who lived in Lower Northern Thailand aged 60 and above, with a total population of $885,606(15)$. The mean estimate of the finite population (16) was measured to calculate the sample size, using the following formula:

$n=\frac{z_{1-\frac{\alpha}{2}}^{2} \sigma^{2}}{d^{2}}$

$n_{\text {Adjust }}=n \times \operatorname{deff}$

where $n$ represents the minimum sample size at a confidence interval $(\mathrm{CI})$ of $95 \%, \mathrm{Z}(0.05)=1.96$, and d denotes the maximum error of the estimate $(10 \%)$ from a standard deviation (SD) of SOB in older adults, according to a previous study (9). The sample size was doubled for cluster sampling, and finally, 1098 individuals were recruited.
Participants were selected using multistage sampling. So, first, cluster sampling was carried out in nine provinces of Lower Northern Thailand. Then, simple random sampling was used in five provinces of Phitsanulok, Uttaradit, Sukhothai, Kamphaeng Phet, and Tak. Second, cluster sampling was used for selecting districts within each province. After a simple random sampling of the districts in each province, five districts were selected from five provinces. Finally, to obtain the proportion of older adults, cluster sampling was performed in each district, followed by simple random sampling to determine the number of Sub-District Health Promoting Hospitals (SDHPH). In each SDHPH, the subjects were selected from the family folder system to minimize the selection bias.

The inclusion criteria were as follows: 1) being aged at least 60 years; 2 ) living in the area for more than six months; 3 ) being able to communicate, and 4) willingness to participate. The exclusion criterion was having a history of psychological disorders because they often have increased levels of threat perception. Five public health professionals were trained as research assistants to minimize information bias. The ethics committee of the Institutional Review Board of Naresuan University approved this study (COA No.: 034/2018). Besides, the objectives of the study were first explained to the participants, and then, if they were agreeing, they were included in the study.

\subsection{Data Collection Instrument}

Data were collected using a researcher-developed questionnaire that consisted of four parts: (a) the first part contained 11 items on demographic characteristics; (b) Part 2 contained 11 items to measure social support, according to a study by House and Kahn (12). The subscales included emotional, psychological, and material resources that were rated on a five-point Likert scale, ranging from one (never) to five (always). The total score ranged from 11 to 55 . According to a study by Kocaleventand (17), social support was rated across three levels, based on the cut-off point: poor, 11 - 25; moderate, 26 - 40; and strong, 41 - 55; (c) Part 3 consisted of 22 items intended to evaluate the neighborhood environment, according to a study by Cerin, Saelens, Sallis, and Frank (18). The six subscales were as follows: c -1) perceived residential density; c - 2) street connectivity; c - 3) infrastructures for walking and cycling; c - 4) aesthetics; c - 5) safety from crime, and c - 6) safety from traffic. The subscales were scored on a five-point Likert scale, ranging from one (strongly disagree) to five (strongly agree), with the total score ranging from 22 to 110 . The total score of the neighborhood environment was rated as follows: low, 22 51; moderate, 52 - 80; and good, 81-110; and (d) part 4 of the questionnaire contained 12 items to evaluate the SOB scale, adopted from the study by Young, Russell, and Powers (2). 
This part had four subscales: $d$-1) membership; $d$ - 2) influence; $d$ - 3) integration and fulfillment of needs; and d 4) shared emotional connection. The subscales were rated on a five-point Likert scale, ranging from one (strongly disagree) to five (strongly agree), with a total score of $12-60$. The total score of SOB was categorized as follows: low, < 27; moderate, 28 - 44; and high, 45 - 60.

The content validity was assessed by five experts. The item-content validity index (I-CVI) ranged from 0.80 to 1.00. Cronbach's alpha coefficients were calculated for each subscale as follows: social support (0.72), neighborhood environment (0.82), and SOB aspects (0.88).

\subsection{Statistical Analysis}

Data were analyzed using SPSS Version 16.0. (19). The demographic characteristics are presented by descriptive statistics. The univariate analysis was used to analyze social support, neighborhood environment, and duration of living in the community. Besides, in the multivariate analyses, outliers were excluded ( $n=258$ ), resulting in a score range of 36 - 59. The assumptions for the outcome, predictors, and standardized residuals were also investigated. To test the hypotheses, a forward stepwise multiple regression analysis was performed, indicating the normality, homoscedasticity, and non-multicollinearity of the data.

\section{Results}

In total 1,098 subjects participated in the current study, 674 females and 424 males. Most of them were in the early old age, married (living with the spouse), and unemployed, with primary education, adequate income, and at least one chronic disease. Also, they were mostly homeowners and members of an older adult club in the community. The mean number of family members was $3.54 \pm 1.76$. The mean duration of living in the community was $52.27 \pm$ 18.53 years (Table 1 ).

\subsection{Social support, Neighborhood Environment, and SOB to the Community}

The mean score of the neighborhood environment was $70.41 \pm 12.37$, which represents the moderate status of the neighborhood environment. The mean scores of social support and SOB were 43.18 and 50.85, respectively, indicating strong social support and good SOB (Table 2).

\subsection{Predictive Factors for $\mathrm{SOB}$ to the Community}

Based on the univariate analyses, only three factors (i.e., social support, neighborhood environment, and duration of living in the community $(\mathrm{P}<0.001))$ were significantly associated with the SOB.

\begin{tabular}{|c|c|}
\hline Characteristics & Values $^{\mathrm{a}}$ \\
\hline \multicolumn{2}{|l|}{ Gender } \\
\hline Male & $424(38.6)$ \\
\hline Female & $674(61.4)$ \\
\hline \multicolumn{2}{|l|}{ Age (years) } \\
\hline Early old (60 - 69) & $550(50.1)$ \\
\hline Middle old (70 - 79) & $370(33.7)$ \\
\hline Late old $(>80)$ & $178(16.2)$ \\
\hline \multicolumn{2}{|l|}{ Marital status } \\
\hline Married and living with the spouse & $636(57.9)$ \\
\hline Single/divorced/widow/separated & $462(42.1)$ \\
\hline \multicolumn{2}{|l|}{ Education $^{b}$} \\
\hline Grade 4 or below & $1016(92.5)$ \\
\hline Above grade 4 & $82(7.5)$ \\
\hline \multicolumn{2}{|l|}{ Still working } \\
\hline Yes & $543(49.5)$ \\
\hline No & $555(50.5)$ \\
\hline \multicolumn{2}{|l|}{ Income adequacy ${ }^{c}$} \\
\hline Always sufficient & $228(20.7)$ \\
\hline Occasionally sufficient & $541(49.3)$ \\
\hline Insufficient & $329(30.0)$ \\
\hline \multicolumn{2}{|l|}{ Chronic illness } \\
\hline Yes & $739(67.3)$ \\
\hline No & $359(32.7)$ \\
\hline \multicolumn{2}{|l|}{ Homeownership } \\
\hline Yes & $1005(91.5)$ \\
\hline No & $93(8.5)$ \\
\hline \multicolumn{2}{|l|}{ Being a member of an older adult club in the community } \\
\hline Yes & $685(62.4)$ \\
\hline No & $413(37.6)$ \\
\hline Number of family members (mean \pm SD) & $3.54 \pm 1.76$ \\
\hline Median (IQR) & $3(2-5)$ \\
\hline $\begin{array}{l}\text { Duration of living in the community (years) (mean } \pm \\
\text { SD) }\end{array}$ & $52.27 \pm 18.53$ \\
\hline Median (IQR) & $51.5(40-68)$ \\
\hline
\end{tabular}

${ }^{a}$ For categorical variables, data are shown as No. (\%), whereas for quantitative variables, data are shown as mean $\pm S D$ and median (interquartile range). bducation was categorized relative to grade 4, as the compulsory level of schooling for Thai people since 1936 (promoted to grade 9 in 2003).

${ }^{\mathrm{c}}$ Income adequacy was categorized subjectively by the sample.

The final model, based on the forward stepwise multiple regression analysis, showed that social support, neighborhood environment, duration of living in the commu- 


\begin{tabular}{lccccc}
\hline Table 2. Scores of Social Support, Neighborhood Environment, and SOB to the Community & & & \\
\hline Variables & Number of Items & Possible Score Range & Score Range & Mean \pm SD & Interpretation \\
\hline Social support & 11 & $11-55$ & $11-55$ & $43.18 \pm 8.24$ & $70.41 \pm 12.37$ \\
Neighborhood environment & 22 & $22-110$ & $12-60$ & $12-60$ & $50.85 \pm 7.44$ \\
SOB to the community & 12 & $12-60$ & Goderate & & \\
\hline
\end{tabular}

nity, and education higher than grade 4 were positively correlated with SOB. Also, the number of family members, always-sufficient income, and occasionally sufficient income were negatively associated with SOB to the community. Univariate analysis and interaction effects were tested, and the results showed that potential confounders and effect modifiers were not significant. All significant variables shown in Table 3 are adjusted.

\section{Discussion}

In the present study, the mean score of the SOB to the community was 50.85 , indicating the good $\mathrm{SOB}$ of the participants. Overall, SOB to the community contributes to community cohesion, which in turn enhances social health and well-being. The mean age of participants was $52.27 \pm 18.53$, mostly lived in the community. Therefore, living in the community for a long time builds an emotional connection, based on a shared history, interests, and concerns, which may play an essential role in maintaining and enhancing the individual's psychological well-being (20). Generally, having a safe, independent, and comfortable life at home and in the community during old age is consistent with the concept of "aging in place", which encourages older people to live in their familiar neighborhood environment (e.g., home) rather than special care facilities (21). Regarding social support, the model indicated that for every one-unit increase in the variable, the predicted value of SOB increases by 0.412. This finding is consistent with previous studies, which showed that social support by family and friends was positively associated with SOB to the community $(9,22)$. Social support is known as a factor that reduces stress. The results of the present study are consistent with previous study from Thailand, which reported that Thai older adults received monetary and nonmonetary support from their children and enjoyed a high level of social support (23). Generally, in the Thai culture, people believe that family members are morally mandated to look after their parents and support them, which is a main contributor to the increased social support. Also, in the present study, $62.4 \%$ of older adults were members of an older adult club in the community; therefore, they were engaged in community activities, which could contribute to the social support experienced by older adults.
This result suggests the impact of the neighborhood environment on health, especially for older adults that have functional limitations.

An appropriate neighborhood environment encourages physical activities, such as walking (24). In the present study, the lowest score was for "infrastructure for walking and cycling" (59.62); therefore, further interventions are required to improve this dimension.

Concerning the duration of living in the community, the findings demonstrated that living in a community for a long period is associated with strong relationships with members of the community, familiarization with the neighborhood environment, emotional connection, and SOB to the community. This finding is in line with the result reported by Winterton and Warburton (25), which concluded that older adults who lived in a rural community for a long time are emotionally tied to that community.

In terms of education higher than grade 4 , this finding may be explained by the fact that older adults with education higher than grade 4 were literate and had a better understanding about the importance of social activities, such as physical activity and community ceremonies; this, in turn, increased their membership, influence, integration, and fulfillment of needs, and shared emotional connection.

This study indicated the importance of improving the neighborhood environment and strengthening social supports to enhance SOB to the community among rural older adults. Therefore, policy-makers should develop plans to improve the neighborhood environment, including walking and cycling infrastructures, aesthetics, and street connectivity. Such plans will increase older adults' ability to live independently in their homes, with high SOB to the community and well-being.

The current study had limitations, including selecting rural participants from only one region of Thailand (five provinces). Therefore, when generalizing the results to populations with different contexts, particularly in urban areas, caution should be taken mainly because these populations are different concerning factors such as social norms, education, and living conditions. Therefore, future studies should focus on older adults living in urban areas to explore their SOB to the community. The results of such studies can be used to design appropriate interventions for 


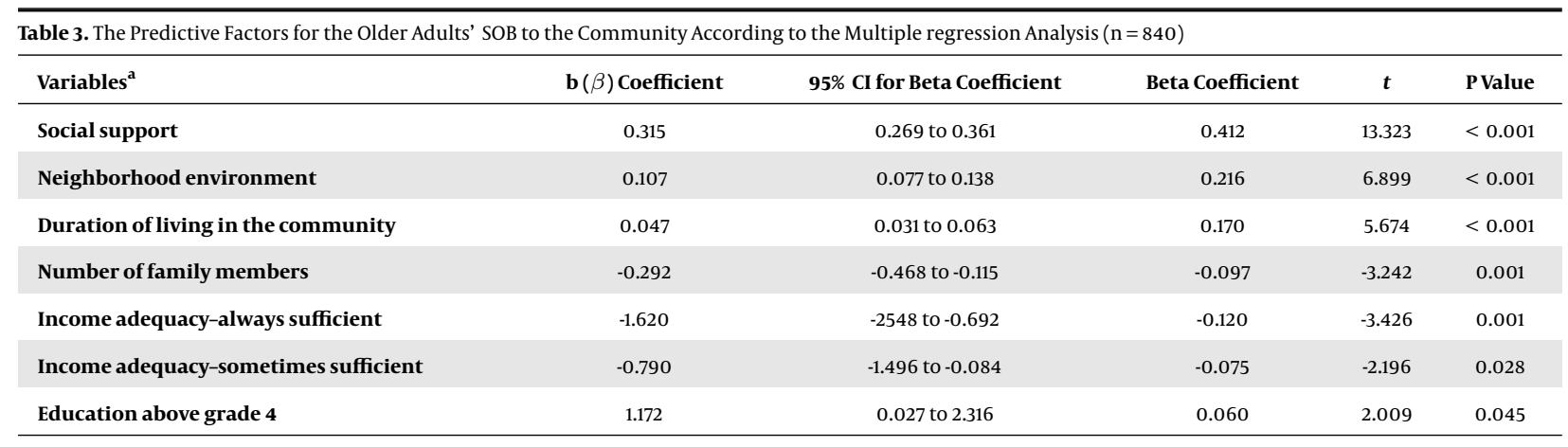

${ }^{\mathrm{a}}$ Constant $=27.80, \mathrm{R}^{2}=0.268$.

seniors to enhance their SOB.

In conclusion, this study showed that education higher than grade 4, duration of living in the community, social support, and neighborhood environment were positively associated with SOB. Future studies are necessary to investigate SOB and its outcomes among older adults, both in urban and rural areas, to implement effective measures intended to improve social support and the neighborhood environment. For this purpose, the population's educational level and duration of living in the community should not be neglected.

\section{Footnotes}

Authors' Contribution: N.K. was the principal investigator, who designed the study, conducted and managed data collection, interpreted the results, and wrote the final manuscript. O.K. contributed to data collection, analyzed the data, and interpreted the results. S.M. contributed to data collection and interpreted the results. All authors approved the final manuscript.

Conflict of Interests: The authors declare no conflict of interest.

Ethical Approval: The Institutional Review Board of Naresuan University approved this study ethically (COA No.: 034/2018; IRB No.: 113/60).

Funding/Support: This study was supported by Provincial Cluster: Lower Northern Provincial Cluster 1 on academic services.

\section{References}

1. Hagerty BM, Lynch-Sauer J, Patusky KL, Bouwsema M, Collier P. Sense of belonging: a vital mental health concept. Arch Psychiatr Nurs. 1992;6(3):172-7. doi:10.1016/0883-9417(92)90028-h. [PubMed:1622293].

2. Young AF, Russell A, Powers JR. The sense of belonging to a neighbourhood: can it be measured and is it related to health and well being in older women? Soc Sci Med. 2004;59(12):2627-37. doi: 10.1016/j.socscimed.2004.05.001. [PubMed: 15474215].
3. Ross N. Community belonging and health. Health Rep. 2002;13(3):339. [PubMed: 12743959].

4. Jakubec SL, Olfert M, Choi LL, Dawe N, Sheehan D. Understanding Belonging and Community Connection for Seniors Living in the Suburbs. Urban Plan. 2019;4(2):43-52. doi: 10.17645/up.v4i2.1896.

5. Yen IH, Shim JK, Martinez AD, Barker JC. Older people and social connectedness: how place and activities keep people engaged. J Aging Res. 2012;2012:139523. doi: 10.1155/2012/139523. [PubMed: 22272374]. [PubMed Central: PMC3261464].

6. Kissane M, McLaren S. Sense of belonging as a predictor of reasons for living in older adults. Death Stud. 2006;30(3):243-58. doi: 10.1080/07481180500493401. [PubMed: 16463466].

7. Kitchen P, Williams AM, Gallina M. Sense of belonging to local community in small-to-medium sized Canadian urban areas: a comparison of immigrant and Canadian-born residents. BMC Psychol. 2015;3:28. doi: 10.1186/s40359-015-0085-0. [PubMed: 26289918]. [PubMed Central: PMC4546026].

8. Choenarom C, Williams RA, Hagerty BM. The role of sense of belonging and social support on stress and depression in individuals with depression. Arch Psychiatr Nurs. 2005;19(1):18-29. doi: 10.1016/j.apnu.2004.11.003. [PubMed: 15765368].

9. Kraithaworn P, Piaseu N. A sense of community belonging and perceived neighborhood environment and facilities in older Thais living in low socioeconomic communities, Bangkok Metropolitan. Rama Nurs J. 2013;19(1):143-56.

10. Karacor EK, Senik B. Understanding sense of community through neighborhood satisfaction and socio-demographic variables. IJHCS. 2016;3(2):1022-35.

11. Cresswell T. Place. In: Kitchin R, Thrift N, editors. International encyclopedia of human geography. Oxford: Elsevier; 2009. p.169-77.

12. House JS, Kahn RL. Measures and concepts of social support. In: Cohen S, Syme LS, editors. Social support and health. Orlando, FL: Academic Press; 1985. p. 83-108.

13. Baumeister RF, Leary MR. The need to belong: desire for interpersonal attachments as a fundamental human motivation. Psychol Bull. 1995;117(3):497-529. [PubMed: 7777651].

14. Bryla M, Burzynska M, Maniecka-Bryla I. Self-rated quality of life of city-dwelling elderly people benefitting from social help: results of a cross-sectional study. Health Qual Life Outcomes. 2013;11:181. doi: 10.1186/1477-7525-11-181. [PubMed: 24168471]. [PubMed Central: PMC3819270].

15. Department of Older Persons. Statistics of the Number of Elderly by Province and Age in 2018. 2018. Available from: http://www.dop.go.th/ th/know/1/159.

16. Daniel WW, Cross CL. Biostatistics: A Foundation for Analysis in the Health Sciences. 10th ed. NJ, United States: John Wiley and Sons Inc; 2013. 
17. Kocalevent RD, Berg L, Beutel ME, Hinz A, Zenger M, Harter M, et al. Social support in the general population: standardization of the Oslo social support scale (OSSS-3). BMC Psychol. 2018;6(1):31. doi: 10.1186/s40359-018-0249-9. [PubMed: 30016997]. [PubMed Central: PMC6050647].

18. Cerin E, Saelens BE, Sallis JF, Frank LD. Neighborhood Environment Walkability Scale: validity and development of a short form. Med Sci Sports Exerc. 2006;38(9):1682-91. doi: 10.1249/01.mss.0000227639.83607.4d. [PubMed: 16960531].

19. IBM Corp. IBM SPSS Statistics for Windows, Version 20.0. Armonk, New York: IBM; 2011.

20. Nowell B, Boyd N. Viewing community as responsibility as well as resource: deconstructing the theoretical roots of psychological sense of community. J Community Psychol. 2010;38(7):828-41. doi: $10.1002 /$ jcop. 20398.

21. Cabinet Office of Japan. International comparison survey on elderly people's livelihood and consciousness. Tokyo: Cabinet Office of Japan; 2007.
22. Tang F, Chi I, Dong X. The Relationship of Social Engagement and Social Support With Sense of Community. J Gerontol A Biol Sci Med Sci. 2017;72(suppl_1):S102-7. doi: 10.1093/gerona/glw187. [PubMed: 28575257]. [PubMed Central: PMC5458425].

23. Knodel J, Teerawitchchainan B, Prachuabmoh V, Pothisiri W. The situation of Thailand's older population: An update based on the 2014 Survey of Older Persons in Thailand Research Collection School of Social Sciences. 2015, [updated December 2015]. Available from: https://ink.library. smu.edu.sg/soss_research/1948/.

24. Kerr J, Rosenberg D, Frank L. The role of the built environment in healthy ageing: community design, physical activity, and health among older adults. J Plan Lit. 2012;27(1):43-60. doi: $10.1177 / 0885412211415283$.

25. Winterton R, Warburton J. Ageing in the bush: The role of rural places in maintaining identity for long term rural residents and retirement migrants in north-east Victoria, Australia. J Rural Stud. 2012;28(4):32937. doi:10.1016/j.jrurstud.2012.01.005. 